\title{
Erratum to: Computer Assisted Proofs of Bifurcating Solutions for Nonlinear Heat Convection Problems
}

\author{
Mitsuhiro T. Nakao - Yoshitaka Watanabe • \\ Nobito Yamamoto • Takaaki Nishida • \\ Myoungnyoun Kim
}

Published online: 3 March 2010

(C) Springer Science+Business Media, LLC 2010

\section{Erratum to: J Sci Comput \\ DOI 10.1007/s10915-009-9303-3}

The name of the fifth author is misspelled in the original publication. The correct spelling is Myoungnyoun Kim.

The online version of the original article can be found under doi:10.1007/s10915-009-9303-3.

M.T. Nakao (凶) · M. Kim

Faculty of Mathematics, Kyushu University, 6-10-1 Higashi-Ku Hakozaki, Fukuoka, 812-8581, Japan e-mail:mtnakao@math.kyushu-u.ac.jp

Y. Watanabe

Research Institute for Information Technology, Kyushu University, Fukuoka, Japan

N. Yamamoto

Department of Computer Science and Information Mathematics, The University

of Electro-Communications, Tokyo, Japan

T. Nishida

Faculty of Science and Engineering, Waseda University, Tokyo, Japan 